\title{
关于现代建筑钢结构工程安装施工与安全防护的探讨
}

张文元

扬州牧羊钢结构工程有限公司

DOI:10.32629/btr.v1i5.1629

[摘 要] 基于现代建筑钢结构工程重量轻、强度高、抗震性能好、施工工期短、回收利用价值高、综合造价低等特征, 使其 被得到广泛应用。因此为了保障建筑钢结构工程质量, 本文对现代建筑钢结构工程安装施工要点及其安全防护管理进行了探 讨分析, 旨在保障钢结构工程建设的顺利进行。

[关键词] 现代建筑; 钢结构工程建设; 安装施工要点; 安全管理; 防护管理

现代建筑钢结构工程具有自重轻以及便于运输和安装, 并且可以有效保护环境等诸多特征。随着科技的进步发展, 使得现代建筑钢结构工程建设不断增多, 因此为了保证现代 建筑钢结构工程建设的顺利实施, 以下就现代建筑钢结构工 程安装施工及其安全防护管理进行了探讨分析。

1 现代建筑钢结构工程安装施工要点分析

1. 1 钢结构工程建设中的螺栓预埋安装施工要点分析 钢结构工程建设中的柱脚与钢筋混凝土基础连接一般 采的用埋入式刚性柱脚螺栓。柱脚螺栓是在安装就位第一节 钢柱时, 控制平面尺寸和标高的临时固定措施。因此, 在预埋 柱脚螺栓时, 应严格控制基础轴线和标高基准点, 定位轴线
的偏差控制在 $\pm 2 \mathrm{~mm}$ 以内, 其标高偏差控制在 $\pm 5 \mathrm{~mm}$ 以内。螺 栓预埋应进行 2 次复测, 第一次在埋设定位后, 第二次在基 础混凝土浇筑并待其坚固后。在复测过程中, 如果发现位移 超出范围, 必须进行重新埋设。

\section{2 钢结构工程建设中的高强螺栓连接安装施工要点分} 析

主要表现为: 第一、运用高强螺栓连接时, 应确保孔位 精确度。目前制孔一般采用模板制孔和多轴数控钻孔, 但后 者的精度高于前者, 在施工时应优先考虑采用后者。第二、 绞孔修整前应保证其四周的螺栓全部拧紧, 使板叠密贴后再 进行。修整时应防止铁屑落人叠缝中。绞孔完成后用砂轮除
大降深应接近工程设计所需的地下水位降深的标高; 水位测 量应采用同一方法和仪器, 读数对抽水孔为厘米, 对观测孔 为毫米; 当涌水量与时间关系曲线和动水位与时间的关系曲 线, 在一定范围内波动, 而没有持续上升和下降时, 可认为已 经稳定; 抽水结束后应测量恢复水位等。(2)不同水文地质 参数测定需要合理选择不同的测定方法。第一、渗透系数、 导水系数: 抽水试验、注水试验、压水试验、室内渗透试验; 第二、测水位: 钻孔、探井或测压管观测; 第三、给水度、 释水系数: 单孔抽水试验、非稳定流抽水试验、地下水位长 期观测、室内试验; 第四、越流系数、越流因数: 多子 L 抽 水试验; 第五、单位吸水率: 注水试验、压水试验; 第六、 毛细水上升高度: 试坑观测、室内试验。(3) 渗水试验和注 水试验可在度坑或钻孔中进行。对砂土和粉土, 可采用试坑 单环法; 对粘性土可采用试坑双环法; 试验深度较大时可采 用钻孔法。(4) 压水试验应根据工程要求, 结合工程地质测绘 和钻探资料, 确定试验孔位, 按岩层的渗透特性划分试验段, 按需要确定试验的起始压力、最大压力和压力级数, 及时绘 制压力与压入水量的关系曲线, 计算试段的透水率, 确定 $\mathrm{P}-$ $\mathrm{Q}$ 曲线类型。

\section{2 基础工程建设中的岩土工程水文地质评价分析}

主要表现为: (1)密切结合建筑物地基基础类型 (如基坑 工程、边坡工程、桩基工程) 和施工需要, 查明有关水文地质 问题, 提供所需的水文地质参数。(2) 岩土工程地质勘察中应
密切结合建筑物地基基础类型, 查明与该地基基础类型有关 的水文地质问题, 提供选型所需的水文地质资料。(3) 评价地 下水对岩土体和建筑的作用和影响, 预测可能产生的岩土工 程危害, 提出防治措施。(4) 按地下水对工程建设的作用与影 响, 提出在不同条件下应当重点评价的地质问题并提出防治 措施。(5) 岩土工程地质勘察不仅要查明地下水的天然赋存 状态和天然条件下的变化规律, 更重要的是分析和预测今后 在人为工程活动影响下地下水的变化情况, 及其对岩土体和 建筑物的不良作用。地下水位的高低对各种建筑物都很重要, 在分析工程地质问题时, 地下水位以上和以下要分别对待。

\section{5 结束语}

综上所述, 基础工程建设中的岩土工程水文地质参数测 定与评价工作对于工程建设顺利实施非常重要, 因此为了保 障基础工程建设质量, 必须做好岩土工程水文地质勘察工作, 所以对其进行分析具有重要意义。

\section{[参考文献]}

[1]孙贵平.分析水文地质问题对工程地质勘查的影响 要点[J].科技与创新,2016,(01):47-48.

[2]匡载斌.岩土工程勘察中水文地质勘察要点分析 [J]. 世界有色金属,2017,(07):39.

[3]廖仁文.岩土工程勘察中的水文地质研究[J]. 西部资 源,2018,(02):28-29. 
去螺栓孔周的毛刺, 同时扫清铁屑。第三、高强度螺栓的安 装在节点全部处理好后进行, 应按同一方向插入螺栓孔内。 对于箱形截面部件的接合部, 全部从内向外插入螺栓, 在外 侧进行紧固。如操作不便, 可将螺栓从反方向插入。

1.3 钢结构工程建设中的吊装施工要点分析

主要表现为:（1）钢柱吊装施工。钢柱是决定层高和建 筑总高度的主要坚向构件, 而吊装是现代建筑钢结构工程施 工的关键工序。第一、在吊装第一节钢柱时, 应在预埋的地 脚螺栓上加设保护套, 以免钢柱就位时碰坏地脚螺栓的丝 牙。钢柱吊装前, 应预先在地面上把操作挂篮、爬梯等固定 在施工需要的柱子部位上。第二、钢柱的吊点设在柱连接耳 板螺栓孔的位置, 采用专用吊索吊装; 钢柱吊装前准备好校 正用的垫板和钢楔, 并将临时高强螺栓等拴牢在柱底连接耳 板处。第三、钢柱垂直起吊至安装位置后, 拧紧临时连接板 的 M22 大六角头高强螺栓, 达到 $0.6 \mathrm{KN}$. $\mathrm{m}$ 扭矩。对正时, 先调 标高, 当标高误差超过 $6 \mathrm{~mm}$ 时, 需进行调整。(2) 钢梁吊装施 工。在钢梁吊装前, 应于柱子牛腿处检查标高和柱子间距。 主梁吊装前, 应在梁上装好扶手杆和扶手绳, 待主梁吊装就 位后, 将扶手绳与钢柱系牢, 以保证施工人员的安全; 为提高 塔吊的垂直运输效率, 对于重量较小的次梁和其他小梁, 可 利用多头吊索一次吊装数根, 有时将梁、柱在地面组装成排 架进行整体吊装, 减少了高空作业时间, 在保证质量的同时, 加快了吊装速度。钢梁起吊就位后, 在对其进行安装的过程 中, 应预留经试验确定的焊缝收缩量 (2-3mm), 并用经纬仪跟 踪检查柱垂直度和倾斜度, 然后调整构件的准确位置, 确保 螺栓孔全部对正, 并放入高强螺栓临时固定。

1.4 钢结构工程建设中的焊接安装施工要点分析

主要表现为: 第一、焊接原则是采用结构对称、节点对 称、全方位对称焊接。多层焊接宜连续施焊, 每一层焊道焊完 后应及时清理、检查, 清除缺陷后再焊。第二、焊接钢结构前, 应严格检查焊条的合格证, 并按说明书要求使用焊条焊接时, 应确保焊缝表面无裂纹、焊瘤, 确保一、二级焊缝无气孔、夹 渣、弧坑、裂纹, 并按要求进行无损检测, 确保一级焊缝不出 现咬边。同时, 还应在规定的焊缝及部位检查焊工的钢印。第 三、坡口电焊连接应先做好准备, 即包括: 采用焊条烘焙; 坡 口检查; 设电弧引人 (引出) 板和钢垫板, 并采用点焊固定; 清 除焊接坡口、周边的防锈漆和杂物; 焊接口预热等。

\section{2 现代建筑钢结构工程安装施工安全管理分析}

现代建筑钢结构工程安装施工安全管理主要表现为: (1) 吊装施工安全管理。现代建筑钢结构工程吊装过程中, 需要 严格执行安全技术标准。吊装前需要对吊装设备进行稳定性 检测, 对吊装的钢丝绳也应做到定期的检查和维护, 以保证 在施工中的顺利进行。吊装中, 必须保证吊装构件重量的相 符, 不能超负荷运作, 会发生失衡或掉落的事故。吊装使用的 钢丝绳也应依据重量使用不同的型号, 不能小型号大使用。 对发生散股或毛刺的钢丝绳, 应做红色标记并及时处理。对 报废的钢丝绳要及时销毁。（2）高空作业安全管理。现代建
筑钢结构工程高空作业施工时, 应配备好使用工具的防护, 预防坠落。例如扭矩扳手、角磨机及㲎棍等, 为避免出现滑 落的现象, 应绑上保护性的安全绳。在彼此间传递工具时, 不能抛掷和远距离传递, 以免滑落或坠落伤人。还应要求施 工人员对螺栓垫片等随手用的工具进行工具袋的放置。在施 工作业过程中应运用撤除或加强固定的方法对有可能出现 坠落的物件进行保护。(3) 操作平台安全管理。操作平台是 现代建筑钢结构工程在高空作业根基, 只有把根基扎实了, 才能保障施工操作安全。操作平台的搭建一般是使用钢管构 件, 各衔接处必须使用焊接, 以达到其稳定性和平衡力。使用 搭建的钢管不能有弯曲或者腐蚀, 搭建必须按长度和宽度都 达到 2 米的标准进行。四周搭建双护栏, 并达到 1.2 米的标 准。坚柱必须垂直于地面, 横柱必须平行于地面, 四周对称, 连接处必须保证牢固。

\section{3 现代建筑钢结构工程安装施工防护管理分析}

现代建筑钢结构工程安装施工防护管理主要体现在: (1) 设置钢柱对接安装操作平台。钢柱要分段安装。对接、螺栓 坚固时, 要在距第一段钢柱柱顶 $1.2 \mathrm{~m}$ 处架高操作平台, 以给 钢柱对接安装、焊缝外观处理、校正、超声波探伤等工序提 供安全生产保障。(2) 铺设走道板。在安装柱、梁后没有设 置压型板时, 需要在钢梁上铺设走道板, 铺设的方法是: 用钢 管搭设成十字网状, 平行间距小于 $300 \mathrm{~mm}$, 固定在钢梁的上翼 缘, 方便下一节柱梁的施工。(3) 加强地面洞口临边的防护。 对地面上的电梯井、管道井和边长大于 $1.5 \mathrm{~m}$ 的洞口周边防 护要设立高 $1.2 \mathrm{~m}$ 的防护栏, 根据《建筑施工高处作业安全 技术规范》要求钢筋防护栏材料必须是立杆 $\phi 18 \mathrm{~mm}$ 、上横杆 $\phi 16 \mathrm{~mm}$ 、下横杆 $\phi 14 \mathrm{~mm}$ 的螺纹钢筋。(4) 应用吊篮进行焊接 作业。焊接作业一般没有固定的操作平台, 这就需要采用吊 篮等悬空设施。焊接操作人员应将安全带挂在钢梁或安全绳 上, 挂篮挂在设有主梁上翼板的挂件上, 为建筑施工中高强 螺栓的终拧、焊缝外观处理和超声波探伤等方面提供了安全 生产的保障。

\section{4 结束语}

综上所述, 城市化建设的不断推进以及科技进步, 促进 了建筑业的快速发展, 使得现代建筑钢结构工程建设不断增 多, 因此在现代建筑钢结构工程安装施工质量、进度及其成 本, 必须加强对现代建筑钢结构工程安装施工要点及其安全 防护管理进行分析。

\section{[参考文献]}

[1]李德强.高层建筑钢结构工程安装施工 [J].建筑技术 开发,2018,(04):79-80.

[2]张忠杰.高层建筑钢结构施工技术要点的思考[J].江 西建材,2017,(04):53+56.

[3]周长宏.钢结构工程施工管理中的安全防护探讨 [ J]. 中国化工贸易,2017,(04):48-49.

[4]马广成.简议工民建钢结构工程建设的安装施工及其 安全防护管理[J].装饰装修天地,2018,(18):78-79. 